\title{
Problem Solving: A Test of Yin-Yang Thinking
}

\author{
Peter C. King $^{1} \&$ Wei Zhang ${ }^{2}$ \\ ${ }^{1}$ Beijing University of Technology, Beijing, China \\ ${ }^{2}$ Management School, University of International Business and Economics, Beijing, China \\ Correspondence: Peter King, Beijing University of Technology, Beijing, China. Tel: 86-138-1167-2410. E-mail: \\ kipet2002@yahoo.com
}

Received: September 10, $2014 \quad$ Accepted: October 13, 2014 Online Published: November 26, 2014

doi:10.5539/jms.v4n4p76 URL: http://dx.doi.org/10.5539/jms.v4n4p76

\begin{abstract}
Yin-Yang thinking and Western views of thinking have been studied, but researchers have not focused on how to demonstrate Yin-Yang thinking compares to Western thinking. The purpose of this study was to test how Yin-Yang thinking and Western thinking could be demonstrated by selection of Chinese and Western students at a Chinese University. The students were asked to demonstrate their understanding of a piece of paradoxical literature in a timed test. We found Chinese Yin-Yang thinking was compatible with Western critical thinking practices but revealed an ability to develop more encompassing creative solutiuons to resolving the given paradox. However, the findings in this research are limited to a small selection of participants and further research is needed to test for general applicability. The use of Yin-Yang thinking enhances the development of insightful solutions to problems.
\end{abstract}

Keywords: Western thinking, Chinese thinking, creative thinking, critical thinking, Yin-Yang thinking

\section{Introduction}

Research has suggested that there are cultural and personal barriers to critical and creative thinking and thus thinking in the West may differ from thinking in China. Recently, whereas the Chinese view of Yin-Yang thinking has been studied, researchers have not focused on how to demonstrate Yin-Yang thinking in comparison with Western thinking. In this paper, we explored whether Chinese Yin-Yang thinking and Western critical thinking practices are compatible.

\section{Literature Review}

The communication of ideas requires cognition (Gu, 2004) and the creation of mental images (Ignatow, 2004) that are developed subconsciously (Cwik, 2011) during normative cognitive development (Leerkes et al., 2008). Human cognition includes both reality and culturally based expressions that embody metaphor and imagination (Ning, 2007) shaped by culture, education, and experience that differs between Western and Chinese cultures (Heffernan et al., 2010; Jin \& Dan, 2004; Mok \& Morris, 2012; Pearce \& Zeng, 2007). Western thinking relies heavily on Aristotelian logic and linear stability; however, Chinese thinking relies heavily on relationships and change (e.g., the Dao; Gou \& Dong, 2011).

Sternberg (1998) suggested human intelligence consists of three components: analytical, creative, and practical abilities, but each individual ability is dependent on the method of instruction (e.g., Sternberg \& Grigorenko, 2004). Moreover, Sternberg and Grigorenko (2004) noted that there are cultural differences in how an individual solves problems and thus cultural contexts should be taken into account when assessing cognitive processes.

\subsection{Critical Thinking}

Dewey (1998) reported that critical thinking is the "active, persistent, and careful consideration of a belief or supposed form of knowledge in the light of the grounds which support it and the further conclusions to which it tends" (p. 9). Critical thinking includes attitudes (Glaser, 1941), decisions (Norris \& Ennis, 1989), and is the examination of why we hold a belief, and the implication of that belief (Fisher, 2011). Whereas an accepted definition of critical thinking is yet to be determined (Baildon \& Sim, 2009; Castle, 2011), Sariolghalam and Noruzi (2010) noted, "All definitions are true and the appropriate one is the one which is most compatible with the researchers' goal" (p. 62).

Whereas a precise definition remains undecided, there is agreement on the salient features of critical thinking 
and why critical thinking is associated with greater problem solving skills (Tümkaya, Aybek, \& Aldağ, 2009). Critical thinking includes judging the validity and reliability of assumptions and of sources of information, making inferences, using envisioning, and using inductive and deductive logic to generate solutions (Baildon \& Sim, 2009; Kirschner, 2011). Fisher (2011) added the identification of relevant elements, clarification and interpretation of ideas, the evaluation of diverse arguments, and the production of arguments. In addition, Cosgrove (2009) added the application of logical inquiry, reasoning, and the ability to participate in critical evaluation.

Critical thinking leads to the production of solutions as well as providing new perspectives on solving problems. However, the presentation of critical thinking as an arranged set of sequential measures fails to recognize how individual elements are interdependent; and that the elements can be complex and ambiguous (Baildon \& Sim, 2009; Helsdingen \& van Merriënboer, 2011; Saiz \& Rivas, 2011). Thus, critical thinking is independent of the context that it occurs, which implies it is impartial, neutral, and apolitical (Baildon \& Sim, 2009; Koh, 2002). However, Abubaker (2008) suggested that Chinese education and cultural factors, such as Confucian beliefs on authority and compliance (Tiwari, Avery, \& Lai, 2003; Yeh \& Chen, 2003) may stifle the development of critical thinking. Therefore, we examined Chinese critical thinking and compared our findings to definitions of critical thinking offered by Dewey (1998), Norris and Ennis (1989), Kirschner (2011), Baildon and Sim (2009), and Fisher (2011).

Critical thinking skills can be learned (Carlson, 2011; Castle, 2011; Crenshaw et al., 2011; Riggs \& Hellyer-Riggs, 2010; Saiz \& Rivas, 2011), but student learning largely depends on ability, motivation, and social context (Grikorenko \& Sternberg, 1997; Pretz, Naples, \& Sternberg (2003). Grigorenko and Sternberg (1997) reported that three additional cognitive styles contributed to success: cognition-centered, personality-centered, and activity-centered. The cognition- and personality-centered approaches are stable, and marked by reflection and sequential actions in thinking. In contrast, activity-centered styles are flexible processes that seek optimal approaches to finding solutions (Grigorenko \& Sternberg, 1997).

\subsection{Creative Thinking}

Creative thinking leads to the production of new paradigms (Wang, 2007). Cheng, Kim, and Hull (2010) noted that creativity and culture interact, and that culture influences the expression of creativity. Culture determines both personal and situational education and thinking styles (Redding, 1980; Sternberg \& Grigorenko, 2004; Tse \& Altarriba, 2008). Moreover, there are linguistic preferences that stem from these differing perspectives about expressing ideas (Tse \& Altarriba, 2008), and small group influences may add additional dimensions to cultural considerations (Eliasoph \& Lichterman, 2003). For instance, social norms such as pressures to conform can create barriers to creativity (Perry-Smith \& Shalley, 2003; Wang, 2007) Thus, creativity depends on personal and situational contexts, including education (Kuttim, Arvola, \& Venesaar, 2009; Kilgour \& Koslow, 2009).

\subsection{I-Ching}

Chinese thinking for millennia has been influenced by the Book of Changes, or I Ching (Fang, 2012: Gibson \& McDaniel, 2010; Gou \& Dong, 2011; Gu, 2004; Qiao \& Chen, 2011; Shaugnessy, 1992). The I Ching explains the dynamic balance between opposites (Gou \& Dong; Slote, 2013) and provides visual representations, or schemas, of the tenets of Yin-Yang thinking (Yang, 2006). Thus, the I Ching may influence Chinese perceptions by acting as an augmentation of Aristotelian thought principles (c.f., Ignatow, 2004; Kirschner, 2011)

\subsection{Yin-Yang and Paradox}

Chinese thinking differs from Western thinking in that Chinese thinking does not accept the Western view of paradox, or "contradictory yet interrelated elements-elements that seem logical in isolation but absurd and irrational when appearing simultaneously" (Lewis, 2000, p. 760). Western views regard a paradox as a problem, whereas in Yin-Yang (i.e., Chinese) thinking contradictions and paradoxes are considered to be a way of life (Fang, 2012).

Recent research has examined Yin-Yang thinking (e.g., Fang, 2012; Jing \& Van den Ven, 2014; Li, 2013), and Fang stated that "Yin-Yang captures the Chinese view of paradox as interdependent opposites compared to the Western view of paradox as exclusive opposites" (p. 26). Indeed, a Yin-Yang view is often called dialectical thinking, which refers to the predisposition to accept inherent contradictions; this differs from the Western views of contradiction as "either/or" (Aristotelian logic), "both/or" (Bohr's complementary principle), or "either/and" (Hegel's dialectic) logic (Li, 2013). A Yin-Yang view holds a "both/and" framework (Fang, 2012, p. 34). Fang (2012) noted that Western views are biased towards absolutes whereas the Yin-Yang view adopts duality by accepting the existence of opposites. 
Several studies have compared Chinese and Western students' thinking styles (e.g., Heffernan et al., 2010; Jones, 2005; Koh, 2002; Liao \& Chen, 2009; Pearce \& Zeng, 2007; Ryan \& Kam, 2007; Tümkaya et al., 2009; van der Walt, 2010; Yang \& Wen, 2004; Yun, 2010). Yet these studies have focused on teaching styles or student-teacher relationships, and no studies have focused on demonstrating how Yin-Yang thinking compares to Western thinking (Liao \& Chen, 2009; Liu, 2005; Yang \& Wen, 2004).

\subsection{A Test of Yin-Yang Thinking}

We examined how Yin-Yang thinking may be compared to critical and creative thinking styles in Chinese and Western students. We developed a test that required participants to find a solution to paradoxes that might provide evidence of critical, creative, or Yin-Yang thinking.

The test was time limited as to include possible tacit knowledge (Insch et al., 2008). We considered that critical and creative thinking could be demonstrated by finding one or more solutions in a test paradox, whereas Yin-Yang thinking would be demonstrated by finding a solution that encompassed all paradoxes in the test.

\section{Methodology}

Chinese and Western postgraduate students attending a Beijing university were selected as participants in this study. The Chinese students were enrolled in English speaking classes and the Western students were enrolled in Chinese studies. The test was administered in 4 groups each of approximately 29 participants. The groups were composed of 66 Chinese post-graduate students and 58 masters-level Western exchange students studying at Beijing University of Technology. The Chinese students came from many parts of China, whereas one group of Western students was from Holland the others came from various Western countries. As graduate students, all participants were considered to have had exposure to critical and creative thinking (Cosgrove, 2009), which is an assumption that may need to be established.

Students' analysis of a piece of English literature containing contiguous paradoxes was used as the testing instrument. Participants were asked to determine if the literature conveyed a logical message, or if it was a collection of nonsense words.

We used a verse from "The Walrus and the Carpenter" (Carroll, 1872) for the test. Carroll has been the subject of comment by several researchers who examined its use of metaphors, paradoxes, logic, and syntax (e.g., Fry, 1987; Kauffman, 2002; van der Walt, 2010). We considered that the chosen piece of literature met the notion of opposite elements appearing simultaneously (Fang, 2012). The chosen verse reads:

"The time has come," the Walrus said,

To talk of many things:

Of shoes--and ships--and sealing wax--

Of cabbages--and kings--

And why the sea is boiling hot--

And whether pigs have wings.

Because the objects in the verse are diverse, we considered that establishing a relationship between any lines in the verse would demonstrate Aristotelian thinking, whereas developing a coherent scenario that included all the objects mentioned in the verse would demonstrate evidence of Yin-Yang thinking. A five-minute discussion took place during which the concepts of critical and creative thinking were explained

The test involved presenting the verse on a power point slide. Test participants were told to read the verse and then the test began. The test was timed and the test conductor participated by giving hints at designated times.

The following hypotheses were considered:

H1: Western and Chinese participants respectively would determine, without hints, the rationality of the piece of literature.

H2: Western and Chinese participants respectively would determine, with hints, rationality in parts of the piece of literature.

H3: Western and Chinese participants respectively would determine a scenario encompassing the whole piece of literature.

Five minutes into the test, the participants were asked to record their opinion of the verse as a whole, specifically, if it was sensical or nonsensical (a yes/no answer). After all participants indicated they had recorded their opinions, the hint "Kings eat cabbages" was given; participants were told how volcanic action could heat the sea; finally, they were asked to consider the possibilities of genetic engineering that hypothetically could produce a 
pig with wings. Participants were then asked to record if they thought any portion of the verse was sensical or if a comprehensive scenario could be developed ( a yes/no answer).. Participants who indicated a comprehensive scenario were asked to give a verbal description of it.

\section{Results}

All students participating in the verbal sessions initially considered the verse nonsensical; therefore, Hypotheses 1 was rejected.

Once the hint "Kings eat cabbages" was added to the list of seemingly unrelated objects in lines three and four, $89 \%$ Chinese and $97 \%$ Western students created further relationships between ships, shoes, sealing wax, cabbages, and kings. Recognition of these relationships supports Hypotheses 2

Seven Chinese and two Western students could not grasp the notion of the metaphor implied by a walrus talking. All students accepted that the sea could be boiling hot near volcanic action. However, all students initially rejected the notion that pigs could have wings until making the connection to the possibility of future genetic engineering. Despite the hint about the discovery of life forms in the hot, toxic waters surrounding fumaroles, no student recognized the implication that life could exist elsewhere (such as on other planets) in hot toxic waters. It may be that students did not project possible implications due to a lack of basic knowledge of natural sciences.

The possibility that future science might develop a pig with wings caused amusement but generally no other comments. The inability to consider the implication of pigs having wings may not indicate resolving a paradox, but may reflect the ability to use inferences, envisioning, and deductive logic to arrive at a possible solution. However, two Chinese students in different groups suggested that if the flying pigs could be encouraged to fly into the boiling sea the result would be instant pork or soup (although no cabbages were included in the recipe). This insight provides some corroboration for Wang (2007). However, for line five and six of the verse, Hypotheses 2 was not supported significantly.

We found that four $(6 \%)$ Chinese students created rational and creative scenarios. Three students explained the verse in terms of national discontent, applying metaphors for failure of social support (e.g., government indifference to poverty as evidenced by eating cabbages and kings wearing shoes while travelling on ships); public outrage (e.g., boiling hot sea); and hopelessness (e.g., when pigs can fly). One student applied engineering principles to the boiling hot sea and flying pigs to establish the concept of a steam powered amphibious ornithopter, capable of transporting a king wearing shoes and consuming state approved (by affixation of a seal) cabbages. Since four Chinese students (and no Western students) presented a coherent scenario, Hypothesis 3 was not supported significantly. The results are summarized in Table 1.

Table 1. Summary of results

\begin{tabular}{llll}
\hline Issue & $\begin{array}{l}\text { Elapsed time } \\
\text { minutes }\end{array}$ & $\begin{array}{l}\text { Chinese students }(\mathrm{N}=66) \\
\mathrm{X}(\%)\end{array}$ & $\begin{array}{l}\text { Western students }(\mathrm{N}=58) \\
\mathrm{Y}(\%)\end{array}$ \\
\hline Verse is nonsensical & $0-2$ & $66(100 \%)$ & $54(93 \%)$ \\
Able to determine relationships after hints given. & $2-22$ & $59(89 \%)$ & $56(97 \%)$ \\
Develop a whole-verse scenario & $22-52$ & & $0(0 \%)$ \\
\hline
\end{tabular}

The results indicate that once critical thinking has been established, both Chinese and Western students applied the principles to establish relationships or scenarios between some, but not all, of the elements in the verse. However, some students displayed evidence of creative thinking.

\section{Discussion}

Westerners consider critical thinking to be an essential element for meeting life's challenges (Cosgrove, 2009) and Chinese individuals rely heavily on relationships and the nature of change (Gou \& Dong, 2011). The results of the test suggested that some (6\%) of the Chinese individuals could rely on both during problem solving; however, the same was not observed in Western students, as they did not develop scenarios that encompassed all elements of the verse. We did not determine if western students could develop coherent scenarios if the students were given more time to complete the test.

We could not conclude that critical thinking among Chinese students differed from critical thinking in Western students. We noted that Chinese students appeared to refrain from making inferences, envisioning, and deductive logic to generate solutions; rather, they formed arguments of different kinds. These differences were appeared to be based on relationships such as for example pigs and hot water lead to soup. 
We considered that the ability to create scenarios with all of the elements demonstrated Yin-Yang thinking because seemingly individual paradoxical subjects were included in the formulation of a coherent whole. We surmize that the iconography of the I Ching helps provide a visual representation of balances in nature and the creation of schemas, which is a factor in the development of Chinese critical thinking (c.f., Ignatow, 2004; Kirschner, 2011). We induce that the ability to establish overall scenarios for the verse is based (probably in part) on Yin-Yang thinking.

We also considered how group characteristics might affect creative thinking. We reasoned that if critical thinking prompts and feedback influence critical and creative thinking then the source of the prompts and feedback (i.e., small group characteristics) becomes pertinent. Thus, if coherence can structure group thinking it can also can establish receptiveness to creative thinking but may hinder creative thinking if other group considerations such as conformity to group norms are of sufficient importance (Eliasoph \& Lichterman, 2003). However, if coherence and conformity to group norms is weak, the relation to creativity will also be weak but may encourage individual creative thinking. Therefore, when conformity is considered a societal objective (as is the case in China), creative thinking could be hindered (Kan, 2010; Wang, 2007).

The test used a piece of Western literature; thus, the responses of the Chinese students may have been influenced by their Chinese cultural experiences. This would appear to have been the case at the beginning of the test. However, the Chinese students extrapolated their understanding once the hints were provided. This result supports those reported by Jones (2005) where Chinese students were exposed to a Western environment and subsequently showed that their critical thinking skills became very similar to their local counterparts (Wang, 2007). Furthermore, Yun (2010) found that most Asian students could adopt effective coping strategies when faced with diffent cultural environments. However, proposing completely new paradigms are eschewed in favor of following other researchers so as not to deviate too radically from the norm (Wang, 2007). Whereas this limited test indicated differences between the Chinese and Western students' abilities to resolve a paradox we believe the belief that Western education encourages expression and that Eastern education stresses adherence to models needs to be revisited (Morris \& Leung, 2010).

Given that critical, creative, and Yin-Yang thinking can be learned (Carlson, 2011; Crenshaw et al., 2011; Kiitim et al., 2009; Riggs \& Hellyer-Riggs, 2010; Saiz \& Rivas, 2011), we examined the education systems in China and the West. In the West, critical thinking has been included in the curricula at various levels of education; however, after the establishment of New China, the teaching of Yin-Yang thinking in Mainland Chinese institutions has disappeared from the curricula, particularly during the Cultural Revolution (1966-1976). Moreover, recent research has suggested the Chinese education system entails rote learning and is geared towards social control and prescribed moral judgments (Kan, 2010). For instance, Liao and Chen (2009) found that argumentative writing is taught differently in Chinese (Hong Kong) schools whereby Chinese textbooks appeal highly to historical and moral issues, while English textbooks suggest using Toulmin's reasoning system.

Xiao and Tong (2010) indicated that there has been a recent swing away from the educational emphasis on rationality following the establishment of New China. There is a need to improve students' ability to apply moral value judgments suggesting that in China the adoption of Western critical and creative thinking is not yet complete. However, in this study, Chinese students were able to extrapolate from the hints; thus, critical and creative thinking were demonstrated. This may suggest that either these abilities are included in the education system or these abilities are subsets of Yin-Yang thinking.

\subsection{Future Research}

The notion of Yin-Yang thinking suggests several avenues of future investigations related to education, training, and research methods. We could not establish the extent to which Chinese traditional curricula and methods have continued. If the existence of New China has reduced the influence of traditional methods, the origin of traditional thinking in Chinese students requires investigation.

Chinese students exposed to Western thinking may have managed to adapt to Western rationality; however, whether Western students exposed to Chinese thinking can similarly adapt is unknown. One possible avenue for future research is the relationship between the I Ching and thinking styles to determine how one method of thinking infuemces the other (c.f., critical thinking; Cosgrove, 2009). Chinese educators have long recognized the value of visual presentation, but the use of the I Ching as a model for the presentation of relationships has not yet been adopted in Western education. We did not determine whether Yin-Yang thinking could inhibit the critical thinking process. 


\subsection{Limitations}

The testing used herein falls far short of the rigorous testing methods used by Sternberg and Grigorenko (2004); and further research is required. Furthermore, as noted by Sternberg and Grigorenko (2004), intelligence is culturally dependent and there may be cultural differences between Chinese and Western students' interpretation of a Western piece of literature. Thus, the finding where Chinese students were able to develop a complete scenario while Western students were not able to do so may be due to cultural differences resulting from Yin-Yang thinking.

The participants in the test represented a small and educated segment of Chinese society and a small segment of Western students, so conclusions cannot be generalized to entire populations. In addition, the responses of the students may have been influenced by other factors. First, proficiency in English among the Chinese students varied, so there may have been language issues that influenced the Chinese students' understanding and responses. Because English is spoken by the students from the western countries we did not factor in language considerations for these stuednts.

Second, the Chinese students may also have been reluctant to record their opinions due to peer pressure to conform to norms (Wang, 2007). Although the Western students represented a specialized group who benefitted from inter university exchange programs, we did not determine whether their status represented an influencing factor.

Whereas we noted that some students were able to develop coherent scenarios, we were unable to determine if other students might do the same in a different context, such as contexts with no classmates present. Further, we did not examine if Yin-Yang thinking and intelligence might be linked. Sternberg (1998) found that intelligence is in part culturally dependent that is influenced by education and social norms. We also did not examine how education and or cultural norms might influence Yin-Yang thinking.

\subsection{Implications}

Critical and creative thinking are essential aspects of cognitive research. White (2002) found deficiencies in Chinese research that resulted in a lack of theory development and contribution to conceptual discourse, a finding that was echoed by other researchers (e.g., Cao \& Li, 2010; Siu, 2010). Our study indicated that Chinese and Western participants demonstrated similar critical thinking abilities; however, some Chinese participants demonstrated more creative thinking than Western participants.

One implication of our findings is that once Chinese participants understood the principles of critical thinking, their creative thinking appeared to be enhanced due to a Yin-Yang approach $(\mathrm{Li}, 2012)$. Indeed, Western readers may encounter difficulties in understanding how creative thinking outcomes were derived perhaps due to a lack of Yin-Yang influence.

White (2002) and Harzing (2006) noted that while most Chinese and Western studies identified behavioral or attitudinal differences between regions, they did not examine the underlying causes these differences (Sternberg and Grigorenko, 2004). Our own experiences as university educators also have noted such differences. Stening and Zhang (2007) noted that educators should be aware of Chinese methodological issues, including an understanding of Chinese culture (Ryan \& Kam, 2007; Silver, 2012).

\subsection{Conclusions}

In this study, we conducted a limited test to determine if Yin-Yang thinking can enhance the production of creative solutions. We found few differences between Chinese and Western participants' ability to use critical thinking; however, we did find that some Chinese participants demonstrated more encompassing creative thinking. Therefore, we suggest that the understanding of Yin-Yang thinking can enhance Western creative abilities, which will provide opportunities in problem solving.

\section{References}

Abubaker, A. (2008). The influence of Chinese core cultural values on the communication behaviour of overseas Chinese students learning English. ARECLS, 5, 105-135.

Baildon, M. C., \& Sim, J. (2009). Notions of criticality: Singaporean teachers' perspectives of critical thinking in social studies. Cambridge Journal of Education, 39(4), 407-422. http://dx.doi.org/10.1080/03057640903352481

Cao, Y. F., \& Li, P. P. (2010). Indigenous research on Chinese leadership: problems and suggestions. Chinese Journal of Management, 7(11), 1704-1709. 
Carlson, S. (2011). Student perceptions of critical thinking Instructional methods: findings in a business curriculum. Proceedings of the Academy of Educational Leadership, 16(1), 11-16.

Carroll, L. (1872). Through the Looking-Glass and What Alice Found There. Retrieved from http://www.jabberwocky.com/carroll/walrus.html

Castle, A. (2011). Generation of a project proposal for an undergraduate literature review: one dimension of critical thinking. International Journal of Therapy and Rehabilitation, 18(4), 190-197. http://dx.doi.org/10.12968/ijtr.2011.18.4.190

Cheng, Y., Kim, K. H., \& Hull, M. F. (2010). Comparisons of creative styles and personality types between American and Taiwanese college students and the relationship between creative potential and personality types. Psychology of Aesthetics, Creativity, and the Arts, 4(2), 103-112. http://dx.doi.org/10.1037/a0017430

Cosgrove, R. (2009). Critical Thinking in the Oxford Tutorial. Thesis submitted to the University of Oxford in partial fulfillment for the degree of M.Sc. in Higher Education.

Crenshaw, P., Hale, E., \& Harper, S. (2011). Producing intellectual labor in the classroom: the utilization of a critical thinking model to help students take command of their thinking. Journal of College Teaching and Learning, 8(7), 13-26.

Cwik, A. (2011). Associative dreaming: reverie and active imagination. Journal of Analytical Psychology, 56, 14-36. http://dx.doi.org/10.1111/j.1468-5922.2010.01888.x

Dewey, J. (1998). How We Think. Dover Publications, London, First published 1909.

Eliasoph, N., \& Lichterman, P. (2003). Culture in interaction. American Journal of Sociology, 108(4), 735-794. http://dx.doi.org/10.1086/367920

Fang, T. (2012). Yin-Yang: a new perspective on culture. Management and Organization Review, 8(1), 25-50. http://dx.doi.org/10.1111/j.1740-8784.2011.00221.x

Fisher, A. (2011). Critical Thinking: An Introduction. Cambridge University Press, Cambridge.

Fry, W. F. J. (1987). Humor and paradox. The American Behavioral Scientist (1986-1994), 30(3), 42. http://dx.doi.org/10.1177/000276487030003005

Gibson, C. B., \& McDaniel, D. M. (2010). Moving beyond conventional wisdom: advancements in cross-cultural theories of leadership, conflict, and teams. Perspectives on Psychological Science, 5(4), 450-462. http://dx.doi.org/10.1177/1745691610375560

Glaser, E. (1941). An Experiment in the Development of Critical Thinking. Advanced School of Education at Teacher's College, Columbia University, New York.

Gou, Y. N., \& Dong, J. (2011). Structure and evolvement of leadership: a study based on Book of Changes. Journal of Management Development, 30(7/8), 766-777. http://dx.doi.org/10.1108/02621711111150263

Grigorenko, E. L., \& Sternberg, R. J. (1997). Styles of thinking, abilities, and academic performance. Exceptional Children, 63(3), 295-312.

$\mathrm{Gu}$, M. D. (2004). Elucidation of images in the book of changes: ancient insights into modern language philosophy and hermeneutics. Journal of Chinese Philosophy, 31(4), 469-488. http://dx.doi.org/10.1111/j.1540-6253.2004.00166.x

Harzing, A. W. (2006). Response styles in cross-national survey research. A 26-country study. International Journal of Cross Cultural Management, 6(2), 243-266. http://dx.doi.org/10.1177/1470595806066332

Heffernan, T., Morrison, M., Basu, P., \& Sweeney, A. (2010). Cultural differences, learning styles and transnational education. Journal of Higher Education Policy and Management, 32(1), 27-39. http://dx.doi.org/10.1080/13600800903440535

Helsdingen van Gog, T., \& van Merriënboer, J. (2011). The effects of practice schedule and critical thinking prompts on learning and transfer of a complex judgment task. Journal of Educational Psychology, 103(2), 383-398. http://dx.doi.org/10.1037/a0022370

Ignatow, G. (2004). Speaking together, thinking together? Exploring metaphor and cognition in a shipyard union dispute. Sociological Forum, 19(3), 405-443. http://dx.doi.org/10.1023/B:SOFO.0000042555.15713.4d

Insch, G. S., McIntyre, N., \& Dawley, D. (2008). Tacit knowledge: a refinement and empirical test of the academic tacit knowledge scale. The Journal of Psychology, 142(6), 561-579. 
http://dx.doi.org/10.3200/JRLP.142.6.561-580

Jin, S. H., \& Dan, J. (2004). The contemporary development of philosophy of education in mainland China and Taiwan. Comparative Education, 40(4), 571-581. http://dx.doi.org/10.1080/0305006042000284556

Jing, R. T., \& Van den Ven, A. (2014). A Yin-yang model of organizational change: the case of Chengdu Bus group. Management and Organization Review, 10(1), 29-54. http://dx.doi.org/10.1111/more.12045

Jones, A. (2005). Culture and context: critical thinking and student learning in introductory macroeconomics. Society for Research into Higher Education, 30(3), 339-354.

Kan, F. (2010). The functions of Hong Kong's Chinese history, from colonialism to decolonization. Journal of Curriculum Studies, 42(2), 263-278. http://dx.doi.org/10.1080/00220271003599165

Kauffman, L. H. (2002). Time, imaginary value, paradox, sign, and Space. In AIP Conference Proceedings, IOP Institute of Physics Publishing, pp. 146-159. http://dx.doi.org/10.1063/1.1503680

Kilgour, M., \& Koslow S. (2009). Why and how do creative thinking techniques work?: Trading off originality and appropriateness to make more creative advertising. Journal of the Academy of Market Science, 37, 298-309. http://dx.doi.org/10.1007/s11747-009-0133-5

Kirschner, S. (2011). Critical thinking and the end(s) of psychology. Journal of Theoretical and Philosophical Psychology, 31(3), 173-183. http://dx.doi.org/10.1037/a0024698

Koh, A. (2002). Toward a critical pedagogy: creating 'thinking schools' in Singapore. Journal of Curriculum Studies, 34(3), 255-264. http://dx.doi.org/10.1080/00220270110092608

Kuttim, M., Arvola, K., \& Venesaar, U. (2011). Development of creative entrepreneurship: opinion of managers from Estonia, Latvia, Finland and Sweden. Verslas: Teorija ir Praktika Business: Theory and Practice, 12(4), 369-378. http://dx.doi.org/10.3846/btp.2011.38

Leerkes, E. M., Paradise, M., O’Brien, M., Calkins, S. D., \& Lange, G. (2008). Emotion and cognition processes in preschool children. Merrill-Palmer Quarterly, 54(1), 102-124. http://dx.doi.org/10.1353/mpq.2008.0009

Lewis, M. W. (2000). Exploring paradox: toward a more comprehensive guide. Academy of Management. The Academy of Management Review, 25(4), 760-776.

Li, P. P. (2012). Toward an integrative framework of indigenous research: the geocentric implications of Yin-Yang Balance. Asia Pacific Journal of Management, 29(4), 849-972. http://dx.doi.org/10.1007/s10490-011-9250-z

Li, X. (2013). Can Yin-Yang Guide Chinese Indigenous Management Research? Management and Organization Review, 10(1), 7-27. http://dx.doi.org/10.1111/more.12042

Liao, M. T., \& Chen, C. H. (2009). Rhetorical strategies in Chinese and English: a comparison of L1 composition textbooks. Foreign Language Annals, 42(4), 695-720. http://dx.doi.org/10.1111/j.1944-9720.2009.01050.x

Liu, L. (2005). Rhetorical education through writing instruction across cultures: a comparative analysis of select online instructional materials on argumentative writing. Journal of Second Language Writing, 14, 1-18. http://dx.doi.org/10.1016/j.jslw.2004.11.001

Mok, A., \& Morris, M. W. (2010). Asian-Americans' creative styles in Asian and American situations: assimilative and contrastive responses as a function of bicultural identity integration. Management and Organization Review, 6(3), 371-390. http://dx.doi.org/10.1111/j.1740-8784.2010.00190.x

Morris, M. W., \& Leung, K. (2010). Creativity East and West: perspectives and parallels. Management and Organization Review, 6(3), 313-327. http://dx.doi.org/10.1111/j.1740-8784.2010.00193.x

Ning, Y. (2007). Heart and cognition in ancient Chinese philosophy. Journal of Cognition and Culture, 7(1/2), 27-47.

Norris, S., \& Ennis, R. (1989). Evaluating Critical Thinking. Lawrence Erlbaum: New Jersey.

Pearce, R. R., \& Zeng, L. (2007). Chinese American post secondary achievement and attainment: a cultural and structural analysis. Educational Review, 59(1), 19-36. http://dx.doi.org/10.1080/00131910600796827

Perry-Smith, J. E., \& Shalley, C. E. (2008). The social side of creativity: a static and dynamic social network perspective. Academy of Management Review, 28(1), 89-106.

Pretz, J. E., Naples, A. J., \& Sternberg, R. J. (2003). Recognizing, defining, and representing problems. The 
Psychology of Problem Solving, 3-30. http://dx.doi.org/10.1017/CBO9780511615771.002

Qiao, Y., \& Chen, Q. (2011). Conflict and balance between Yin and Yang: a comparison of family values in the book of change and the book of rites. Frontiers Of Literary Studies In China, 5(3), 413-431. http://dx.doi.org/10.1007/s11702-011-0136-8

Redding, S. G. (1980). Cognition as an aspect of culture and its relation to management processes: an exploratory view of the Chinese case. Journal of Management Studies, 17(2), 127-148. http://dx.doi.org/10.1111/j.1467-6486.1980.tb00080.x

Riggs, L., \& Hellyer-Riggs, S. (2010). Overcoming egocentric and socio-centric thought: from knowledge to commitment in critical thinking. The International Journal of Learning, 17, 222-227.

Ryan, J., \& Kam, L. (2007). False dichotomy? 'Western' and 'Confucian' concepts of scholarship and learning”. Educational Philosophy and Theory, 39(4), 404-417. http://dx.doi.org/10.1111/j.1469-5812.2007.00347.x

Saiz, C., \& Rivas, S. F. (2011). Evaluation of the ARDESOS program: an initiative to improve critical thinking skills. Journal of the Scholarship of Teaching and Learning, 11(2), 34-51.

Sariolghalam, N., \& Noruzi, M. (2010). A survey on the relationship between critical thinking and self-efficacy case study: mathematic students of Payam e Noor University in Maragheh. Studies in Mathematical Sciences, 1(1), 61-66.

Shaughnessy, E. L. (1992). Marriage, divorce, and revolution: reading between the lines of the book of changes. The Journal of Asian Studies, 51(3), 587-599. http://dx.doi.org/10.2307/2057951

Silver, N. (2012). The Signal and the Noise: Why So Many Predictions Fail - but Some Don't. The Penguin Press: New York.

Siu, K. M. (2010). Meeting the new needs: design research education in China. Research in Higher Education Journal, 6, 1-19.

Slote, M. (2013). Updating yin and yang. $D a, 271-282$. http://dx.doi.org/10.1007/s11712-013-9328-z

Stening, B., \& Zhang, M. (2007). Methodological challenges confronted when conducting management research in China. International Journal of Cross Cultural Management, 7(1), 121-142. http://dx.doi.org/10.1177/1470595807075179

Sternberg, R. J. (1998). Applying the triarchic theory of human intelligence in the classroom. In R. J. Sternberg \& W. M. Williams (Eds.), Intelligence, instruction, and assessment (pp. 1-15). Lawrence Erlbaum Associates, Mahwah, NJ.

Sternberg, R. J., \& Grigorenko E. L. (2004). Intelligence and culture: how culture shapes what intelligence means, and the implications for a science of well-being. Philosophical Transactions: Biological Sciences, 359, 1449. http://dx.doi.org/10.1098/rstb.2004.1514

Tiwari, A., Avery, A., \& Lai, P. (2003). Critical thinking disposition of Hong Kong Chinese and Australian nursing students. Journal of Advanced Nursing, 44(3), 298-307. http://dx.doi.org/10.1046/j.1365-2648.2003.02805.x

Tse, C. S., \& Altarriba, J. (2008). Evidence against linguistic relativity in Chinese and English: a case study of spatial and temporal metaphors. Journal of Cognition and Culture, 8, 335-357. http://dx.doi.org/10.1163/156853708X358218

Tümkaya S., Aybek, B., \& Aldağ, H. (2009). An investigation of university students' critical thinking disposition and perceived problem solving skills. Egitim Arastirmalari-Eurasian Journal of Educational Research, 36, 57-74.

van der Walt, C. (2010). Of shoes-and ships-and sealing-wax: a dynamic systems approach to language curriculum orientation. Southern African Linguistics and Applied Language Studies, 28(4), 323-337. http://dx.doi.org/10.2989/16073614.2010.548020

Wang, H. (2007). On Ge Wu: recovering the way of the great learning. Philosophy East and West, 57(2), 204-226. http://dx.doi.org/10.1353/pew.2007.0028

White, S. (2002). Rigor and relevance in Asian management research. Where are we and where can we go? Asian Pacific Journal of Management, 19, 287-352. http://dx.doi.org/10.1023/A:1016295803623

Xiao, P., \& Tong, H-S. (2010). Aims and methods of civic education in today's universities of China. Asian Social Science, 6(4), 44-48. http://dx.doi.org/10.5539/ass.v6n4p44 
Yang, Q-Z. (2006). On the Dao in the commentary of the book of change. Frontiers of Philosophy in China, 4, 572-593. http://dx.doi.org/10.1007/s11466-006-0026-3

Yang, S. C., \& Wen, C. L. (2004). The relationship among creative, critical thinking and thinking styles in Taiwan high school students. Journal of Instructional Psychology, 31, 33-45.

Yeh, M. L., \& Chen, H. H. (2003). Comparison affective dispositions toward critical thinking across Chinese and American baccalaureate nursing students. Journal of Nursing Research, 11(1), 39-45. http://dx.doi.org/10.1097/01.JNR.0000347617.29413.96

Yun, Y. (2010). Cultural adaptation of Chinese-background students in an Australian tertiary context. The International Journal of Learning, 17(4), 335-343.

\section{Copyrights}

Copyright for this article is retained by the author(s), with first publication rights granted to the journal.

This is an open-access article distributed under the terms and conditions of the Creative Commons Attribution license (http://creativecommons.org/licenses/by/3.0/). 